\title{
Airway Compromise
}

National Cancer Institute

\section{Source}

National Cancer Institute. Airway Compromise. NCI Thesaurus. Code C121626.

The inhibition of normal respiration by physical obstruction(s) to the airway. 